
78 巻 785 号 2012-1)

\title{
単一上昇気泡の気泡後流とジグザグ運動との相互関係*
}

\author{
橘 倫太郎 ${ }^{* 1}$, 齋藤 隆之*2,3

\section{Relation between Wake and Zigzag Motion of a Single Bubble} \\ Rintarou TACHIBANA and Takayuki SAITO*2 \\ *2 Graduate School of Science and Technology, Shizuoka University \\ 3-5-1 Johoku, Naka-ku, Hamamatsu, Shizuoka 432-8561, Japan \\ In the present study, a transition mechanism to explain the change in the motion of a single ascending bubble from linear to \\ zigzag was investigated experimentally. We focused on the relationship between bubble motion (gravity-center motion and \\ surface motion) and hairpin-like vortex motion. First, the bubble motion was visualized using the infrared shadow technique \\ (IST), and the gravity-center motion and surface motion were quantified. Second, the bubble wake structure and its motion \\ were visualized with the laser induced fluorescence using HPTS (LIF/HPTS) method. From the LIF results, position \\ fluctuations of the point of the hairpin-like vortex leg on the bubble rear surface (wake motion) were quantified. From these \\ results, a close relation between the bubble motion and the wake motion was discussed. Furthermore, a relation between the \\ wake motion and the lift force acting on the bubble was discussed. We concluded that the relations between them play an \\ important role in zigzag motion. In addition, we tentatively concluded that bubble shape deformation observed just after the
} launch was the first trigger for the zigzag motion.

Key Words : Gas - Liquid Two-Phase Flow, Bubble, Wake, Vortex, Flow Visualization

\section{1. 緒言}

気泡流は, 化学プラントや熱交換器, 環境プラント ${ }^{(1)}$ を始めとする, 様々な工業装置内で見られる複雑流動現象である. その流動は, 単一気泡が誘起する局所的な液相運動から, 気泡群, 気泡流周囲の対流に至るまで, スケ一ルの異なる階層流 動構造を呈する. 気泡と周囲液相の相互作用，さらには各階層間での相互作用により流動構造は非線形性が強くなり，非常 に複雑となる ${ }^{(2)}$. これらの流動構造を解明するためには, 気泡流を構成する単一気泡に関する深い知見が必要不可欠となる. 水中を上昇運動する単一気泡は，その径に応じて軌道を変化させ，径が $1.3 \mathrm{~mm}$ 以下の気泡と径が $4.2 \mathrm{~mm}$ 以上の気泡は直 線軌道を描く ${ }^{(3)}$. 一方, 径の值がその中間值にある気泡は, ジグザグ・螺旋運動を呈し ${ }^{(3)}$, Lunde ら $^{(4)}$ の報告に代表されるよ うに，特徴的かつ複雑なへアピン渦を放出する. また，Motarjemi ら ${ }^{(5)}$ は，このサイズの気泡の物質移動速度が最大值を取 ると述べている. 工業技術上も，このサイズの気泡の諸現象を把握することが重要と考える.

これまでジグザグ軌道を呈する単一気泡が誘起する流動を理解するために, 実験で得られた結果を基に多様な研究が進め られてきた. Brücker ${ }^{(6)}$ は, 気泡の形状変形 (アスペクト比により評価) と気泡の後流構造との関係から, 後流のヘッド部か らの渦の放出が気泡の形状変形に影響を及ぼすと報告した. 多くの研究者が気泡形状をアスペクト比で整理したのに対し, 宮本・齋藤( は，気泡の左右両エッジ部に内接円を当てはめ，その曲率で気泡界面運動を定量化した. 彼らは気泡の左右工 ッジ部の形状変形には位相差があり，それが気泡のジグザグ運動を特徵付けると報告した．また，山本ら ${ }^{(8)}$ は低周期でかつ 変動の振幅が大きい界面振動を有する気泡が物質移動を促進すると報告している. すなわち, 物質移動現象を詳細に議論す る上でも，気泡界面運動は重要な役割を果たすものと考えられる.

DNS (Direct Numerical Simulation)により得られた結果による研究報告も非常に興味深い. Magnaudet ${ }^{(9)}$, Mougin ら ${ }^{(10)}$ は, 気泡の直線軌道とジグザグ軌道との違いはその後流の挙動にあるとしている. 彼らは気泡後流の不安定性が, ジグザグ軌道

* 原稿受付 2011 年 7 月 22 日

*1 学生員, 静岡大学大学院 工学研究科（广432-8561 静岡県浜松市中区城北 3-5-1）

*2 正員, 静岡大学創造科学技術大学院

*3 静岡大学工学部

E-mail: ttsaito@ipc.shizuoka.ac.jp 
に深い影響を及ぼすとした. すなわち, 気泡後流の挙動が気泡に働く揚力を誘起していると論じた. また, 気泡後流が不安 定性を有寸る原因について，気泡界面で生成される渦という視点からそのメカニズムを提案した.

上述のように, 気泡後流と気泡形状変形との相互関係は, ジグザグ運動のメカニズムを理解する上で重要な役割を果たす と考えられる. しかしながら, 時々刻々と変化する気泡形状（気泡左右エッジ部の非刘称性）と気泡後流との相互関係が, 十分に理解されたとは言い難い.

本研究では, ジグザグ上昇運動を呈する単一気泡を対象とし, その気泡運動と気泡後流との相互関係を考察することを目 的とする.この相互関係を議論の軸として, 気泡が直線運動からジグザグ運動に遷移するメカニズムを提案する. まず, 特 徵的な界面の形状変形, 後流構造・運動を可視化し, 気泡界面運動と気泡後流との相互関係を定性的に考察寸る. 次に, 気 泡後流の気泡底部での渦の足の位置の変動に着目し, 定量化することで, 形状変形を考慮した気泡運動との関係を定量的に 比較した. また，射出直後の気泡の変形に着目し，気泡後流・気泡運動に及ぼす影響を考察する. これらの考察を基に，単 一気泡が直線運動からジグザグ運動に遷移するメカニズム, 寸なわち, 気泡運動・気泡後流それぞれの変動の位相差から, どの現象が支配的であるかを定量的に考察する.

\section{2. 実験装置と可視化手法}

\section{$2 \cdot 1$ 実験装置}

図 1 に実験装置の概略を示す.アクリル製水槽 (a) $\left(100 \times 100 \times 300 \mathrm{~mm}^{3}\right)$ に煮沸脱気したイオン交換水 (b) $\left(25.7 \pm 0.1^{\circ} \mathrm{C}\right)$ を深さ $270 \mathrm{~mm}$ まで満たした. 水槽底中央部に外径 $0.60 \mathrm{~mm}$, 内径 $0.32 \mathrm{~mm}$, 刃面角度 $12 \circ$ の注射 針 (c)（TERUMO 製：23G×1·1/4”）を鉛直に取り付けた。注射針を用いることにより，気泡がドリフト寸る方向 を任意に制御できる.オーディオスピーカーと二つの圧カコントローラー等からなる気泡射出制御装置 ${ }^{(11)}(\mathrm{d})$ を用 いて二酸化炭素気泡を生成・射出し, 気泡の径, 軌道, 姿勢, 界面運動の全てが高い再現性を有する条件下(12)で 実験を行った. 気泡の重心位置の平均值に対寸る不確かさは，2％以内であった. ファンクションジェネレータ 一 (e)を用いて気泡の発生を制御するとともに, TTL（Transistor-Transistor Logic）信号を 2 台の高速度ビデオカメ

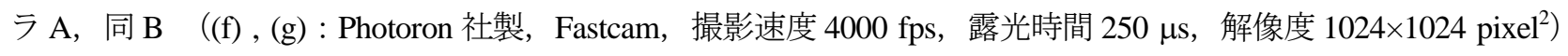
と同期させた. カメラにマイクロズームレンズを装着し, 空間分解能 $16.0 \mu \mathrm{m} / \mathrm{pixel}$ で撮影を行った. 気泡の輪郭 抽出には LED（Light Emitting Diode）(h)（波長 $660 \mathrm{~nm}$ ）を用い，IST（Infrared Shadow Technique）法 ${ }^{(13)} に よ り$ 可 視化した. IST 法は, LED を用いて気液界面を可視化する手法である. カメラ Aにより $y-z$ 平面における気泡運 動と, シート光と気泡との位置関係を撮影し, カメラ Bにより $x-z$ 平面の気泡運動を可視化した. なお, 注射針 と気泡射出制御装置を用いることにより, $y$ 方向への気泡の重心移動が無視できる条件下で実験を行った. $x-z$ 平 面の気泡の水平方向への振幅 $10 \mathrm{~mm}$ に対し, $y-z$ 平面では $0.1 \mathrm{~mm}$ であり, 気泡は $x-z$ 平面を二次元運動すると考 えて良い. シート光に対して, 気泡を常に同じ位置で通過させることが可能であった. さらに, 先行気泡が作っ

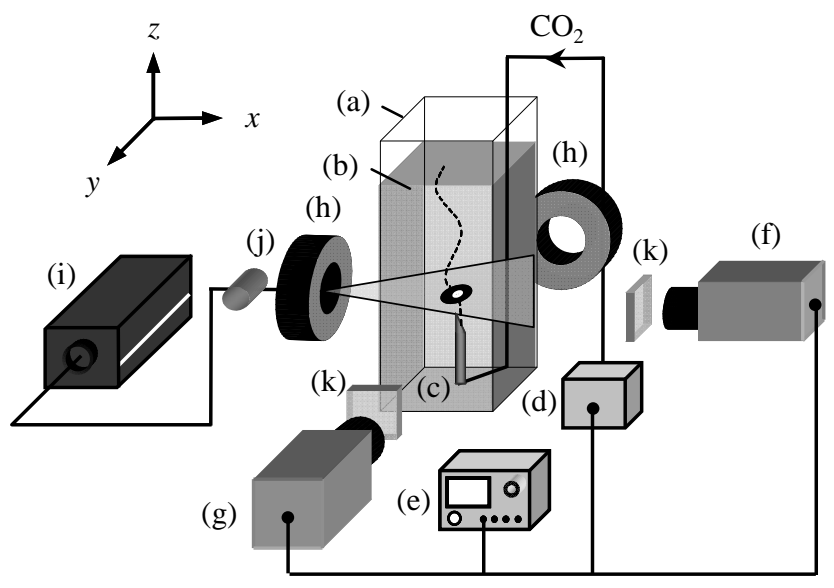
(a) Water Vessel
(b) Water \& HPTS
(c) Hypodermic needle
(d) Bubble-launch device
(e) Function generator
(f) High-speed video Camera A
(g) High-speed video Camera B
(h) Red LED
(i) Ar+ion laser
(j) Rod lens
(k) Sharp cut filter

Fig. 1 Schematic of Experimental setup used in LIF/HPTS. 
た液相運動が消失するのに十分な時間間隔（120 秒）を取ったので，気泡運動，液相運動ともに同一気泡による ものとみな寸ことができる ${ }^{(12)}$. 射出直後の扁平楕円体と見なせる区間において，対象気泡の球等価径 $D_{e q}$ を算出 したところ $2.7 \mathrm{~mm}$ となった。可視化画像から気泡輪郭を抽出する際の画像処理（二值化，境界抽出，輪郭の極 座標表示）により誤差が生じる，誤差の主な原因は二值化であるが，宮本・齋藤の手法 ${ }^{(7)}$ を参考にし，二值化の 值に充分注意した．ピクセル誤差に起因する気泡形状の不確かさは土1\%であった。

気泡運動と同時に, LIF/HPTS（Laser Induced Fluorescence using HPTS）法を用いて, 溶解過程を可視化した. LIF 法は，レーザーと蛍光物質を用いて流速や温度を可視化する手法である. 本研究では, 蛍光物質として HPTS

(8-hydroxypyrene-1, 3, 6-trisuluhonic acid) を用い, アルゴンイオンレーザー (i) (Coherent 社製 : INNOVA 30C, 波 長 $488 \mathrm{~nm}$ ）により励起した。 レーザーから発振されたレーザービームは, ロッドレンズ (j)によりシート状にし て計測領域に照射した．気泡界面からの反射光（488 nm）を除去し，励起された光（520 nm）のみを抽出するた めにシャープカットフィルター (k)（シグマ光機社製 : $500 \mathrm{~nm}$ ハイパス）を用いた.

\section{$2 \cdot 2$ LIF/HPTS 法の原理}

HPTS の発光強度は $\mathrm{pH}$ に依存し，特に $\mathrm{pH}$ 6 9 亿おける発光強度の変化が顕著である ${ }^{(14)}$. HPTS は温度依存性

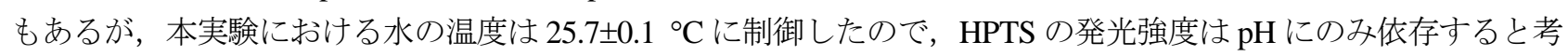
えてよい. 発光強度 $I\left[\mathrm{~W} / \mathrm{m}^{3}\right]$ は式（1）で表される。

$$
I=I_{0} C \phi \varepsilon
$$

ここで, $I_{0}\left[\mathrm{~W} / \mathrm{m}^{2}\right]$ は入射励起光束, $C\left[\mathrm{~mol} / \mathrm{m}^{3}\right]$ は蛍光試薬の濃度, $\phi[-]$ は量子効率, $\varepsilon\left[\mathrm{m}^{2} / \mathrm{mol}\right]$ はモル吸光係数であ る. 本研究の気相は二酸化炭素である. 寸なわち, 二酸化炭素が溶解した部分の液相は, $\mathrm{pH}$ が低くなるため, HPTS の発光強度が著しく低下する. なお, 式 (2), （3）にシュミット数, シャーウッド数の定義式を示す.

$$
\begin{gathered}
S c=v_{L} / D_{G \rightarrow L} \\
S h=k_{L} D_{e q} / D_{G \rightarrow L}
\end{gathered}
$$

ここで, $v_{L}\left[\mathrm{~m}^{2} / \mathrm{s}\right]$ は動粘度, $D_{G \rightarrow L}\left[\mathrm{~m}^{2} / \mathrm{s}\right]$ は二酸化炭素の拡散係数, $k_{L}[\mathrm{~m} / \mathrm{s}]$ は物質移動係数, $D_{e q}[\mathrm{~m}]$ は気泡球等価径 である. なお, 物質移動係数の算出には, 土屋らの方法(15)を参考にした. シュミット数は, 496.1, シャーウッド 数は 707.0 であった. 寸なわち, 速度境界層は濃度境界層に比べて十分に厚く, この薄い濃度境界層が対流によ り気泡後流中にダイレクトに輸送されると考えてよい. LIF/HPTS 法を用いることにより, 気泡界面から溶解した 二酸化炭素が輸送される動的過程と気泡後流の構造を同時に可視化できる ${ }^{(16)}$. なお，気泡後流を鮮明に可視化す るために充分な発光強度を得るために, $\mathrm{NaOH}$ を加えることにより, 溶液の $\mathrm{pH}$ を $7.5 \pm 0.1$ に調整した.

\section{3. 実験結果及び考察}

\section{$3 \cdot 1$ ジグザグ運動と気泡界面運動の相互関係}

本実験における気泡レイノルズ数・ウェーバー数はそれぞれ, $R e=877, W e=3.2$ であった.

$$
\begin{gathered}
R e=w D_{e q} / v \\
W e=\rho_{L} w^{2} D_{e q} / \sigma
\end{gathered}
$$

ここで, $w[\mathrm{~m} / \mathrm{s}]$ は鉛直上昇速度， $v\left[\mathrm{~m}^{2} / \mathrm{s}\right]$ は動粘度， $\rho_{\mathrm{L}}\left[\mathrm{kg} / \mathrm{m}^{3}\right]$ は液相密度， $\sigma[\mathrm{N} / \mathrm{m}]$ は表面張力である.

対象気泡はジグザグ運動を呈し，その界面はモード 2,0 もくは，2,2で振動する ${ }^{(17)}$. 多くの研究者は，気泡の 形状振動をアスペクト比で整理しているが，時々刻々と変形する気泡の左右の非対称性を定量的に表現する上で は, 十分とは言い難い. そこで, 本研究では, 宮本・齋藤が提案した「左右エッジ部の曲率 $\left(\kappa_{\mathrm{L}}=1 / R_{L}[1 / \mathrm{mm}], \kappa_{R}=1 / R_{R}\right.$ 


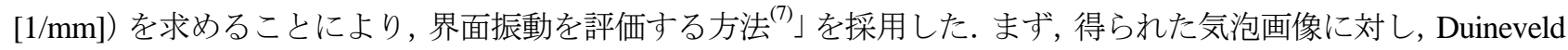

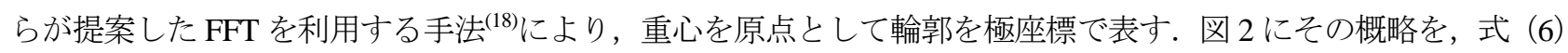
にその定義を示す.

$$
r(\theta)=A_{0}+\sum_{n=1}^{N}\left(A_{n} \cos n \theta+B_{n} \sin n \theta\right)
$$

$A_{n}$ および $B_{n}$ を算出する際の FFT のモード次数は 8 とした. また, $r(\theta)$ が最大となる $\theta$ を $\theta_{1}$ とし, 式（7）により 左右の曲率を算出した. 右エッジ部の曲率を算出する際には $\theta_{1}$ を, 左エッジ部の曲率を算出する際には $\theta_{1}+\pi を$ それぞれ代入した。

$$
\kappa(r, \theta)=\frac{r^{2}+2(d r / d \theta)^{2}-r\left(d^{2} r / d \theta^{2}\right)}{\left[r^{2}+(d r / d \theta)^{2}\right]^{2 / 3}}
$$

図 3 に, 気泡重心運動, 左右エッジ部の曲率変動の時系列データを示す.ジグザグ軌道の周期および平均振幅 は，それぞれ $7 \mathrm{~Hz} ， 3 \mathrm{~mm}$ ，左右の曲率の周期は約 $70 \mathrm{~Hz}$ であった．気泡射出直後 $[0.0 \mathrm{~s}]$ からジグザグ軌道の第一 変向点 $[0.05 \mathrm{~s}]$ までは, 気泡の重心は直線軌道を描き, また, その形状は左右対称な扁平楕円体であった. しかし, 第一変向点 $[0.05 \mathrm{~s}]$ 以降は, 気泡右エッジ部の振幅が左エッジ部に比べて大きくなった. さらに, 第一変向点から 第二変向点に向かう際には, 左エッジ部の振幅が増加し, 第二変向点の手前でその值は最大となった. 相互相関 関数により, 気泡両エッジ部の位相差を算出したところ，ジグザグ運動の半周期に相当する $\pi$ [rad $]$ 差が生じて いることがわかった.

また, 図 3 に第二変向点以降における, 各変向点間(各破線間)における左右の曲率の変動の高周波成分の周期 の数を示す(4)，(5)，(7)）．各変向点間（ジグザグの半周期）の左右それぞれのエッジ部の変動の周期の数は異な り，右エッジ部では 4 周期と 7 周期を交互に繰り返し，左エッジ部では 5 周期のみを繰り返した．この周期数の 遷移と偏りは，気泡のドリフト上昇運動と深い関係があると考えられる．この点に関しては，PIV による周囲液 相運動の可視化結果を合わせて, 今後の課題としたい.

このように, 左右エッジ部の形状の非対称性がジグザグ運動を特徵付け，また，図に示されるように周期的に この変動が繰り返される，ここで，疑問として浮かび上がってくるのが，気泡の左右非対称性が何に起因するの かということならびに気泡界面運動と周囲液相運動との相互関係である. Gaudlitz ら ${ }^{(19)}$ が報告しているように,

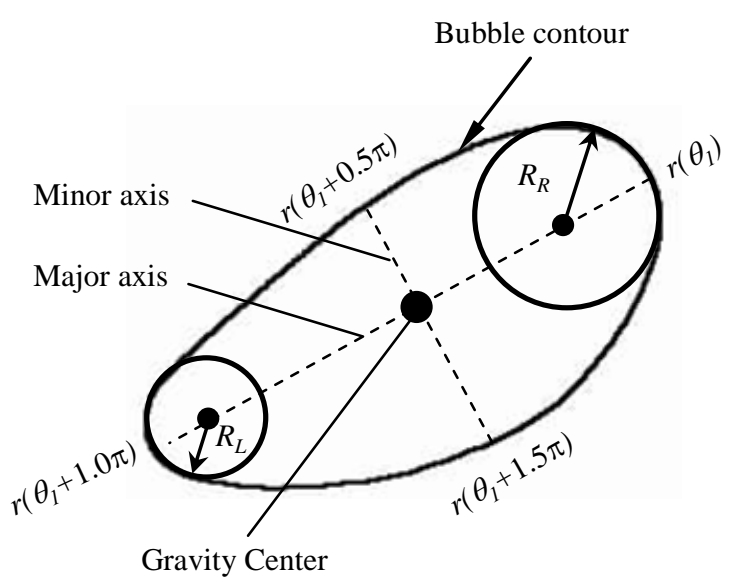

Fig. 2 Evaluation of axes and curvatures.

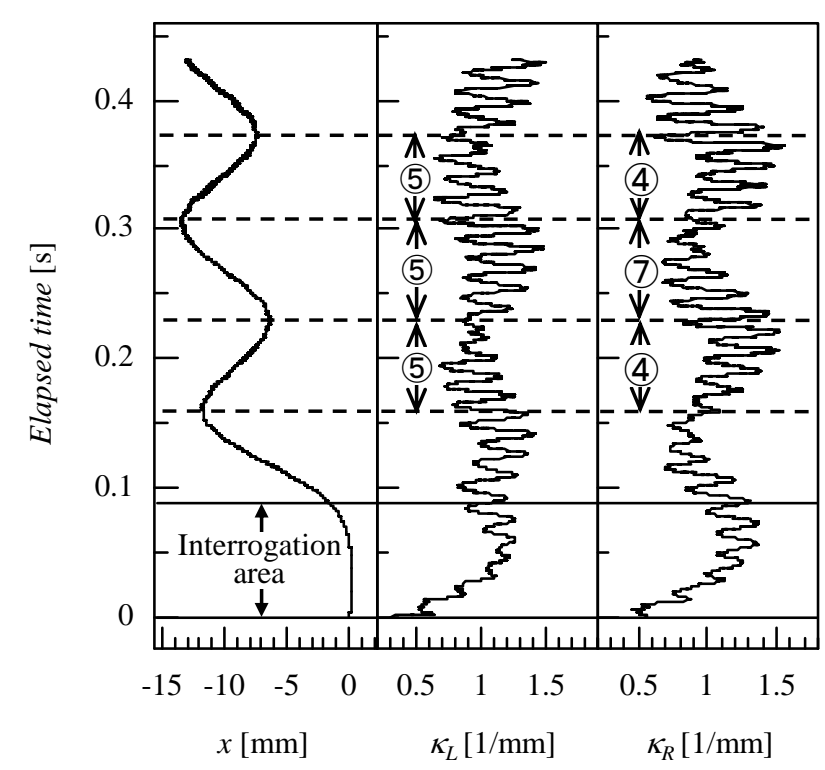

Fig. 3 Overall trajectory and surface oscillations. 
周期的な界面運動と気泡後流（周囲液相運動）には深い関係がある．次節では，気泡後流の気泡底部での運動に 着目し，その運動を定量化することにより，気泡界面運動と気泡後流の運動との相互関係を論じる.

\section{$3 \cdot 2$ 気泡界面運動と気泡後流の相互関係}

図 4 に, 気泡射出直後からジグザグ軌道の第一変向点付近における, 溶解過程の可視化結果を示す. 可視化結 果において気泡後方で輝度值が低くなっている部分は，気泡界面から溶け出した薄い濃度境界層が，厚い速度境 界層の中に含まれている部分である，すなわち，気泡後方の黒い部分は，気泡後流の一部を捉えている部分であ る. 図 4(A)に, 被写界深度の違いによる気泡後流の可視化結果の相違を示寸．被写界深度が高い(a)においては,

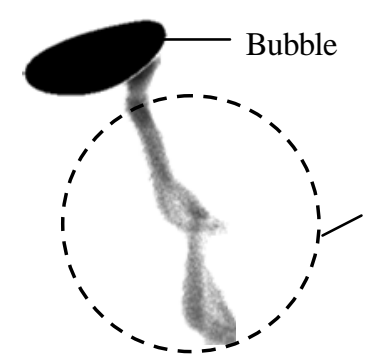

(a) Deep focal depth

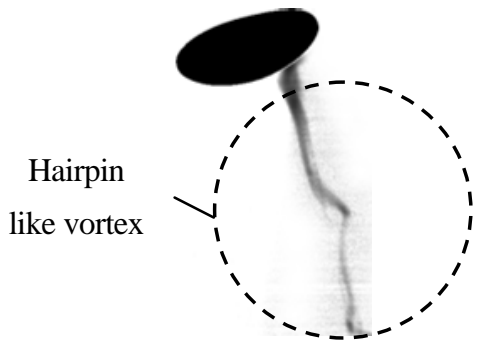

(b) Shallow focal depth

(A) Flow visualization pattern, depending on the camera conditions.

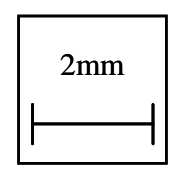

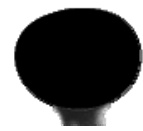

(a) $t_{0}[\mathrm{~s}]$

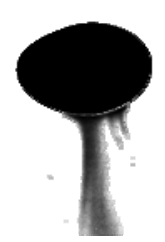

(b) $t_{0}+0.01[\mathrm{~s}]$

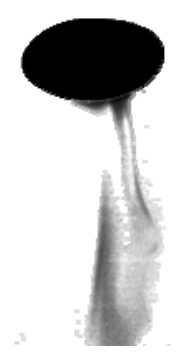

(c) $t_{0}+0.02[\mathrm{~s}]$

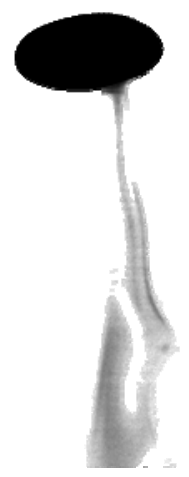

(d) $t_{0}+0.03[\mathrm{~s}]$

(B) Wake motion observed just after bubble was launched from a needle.

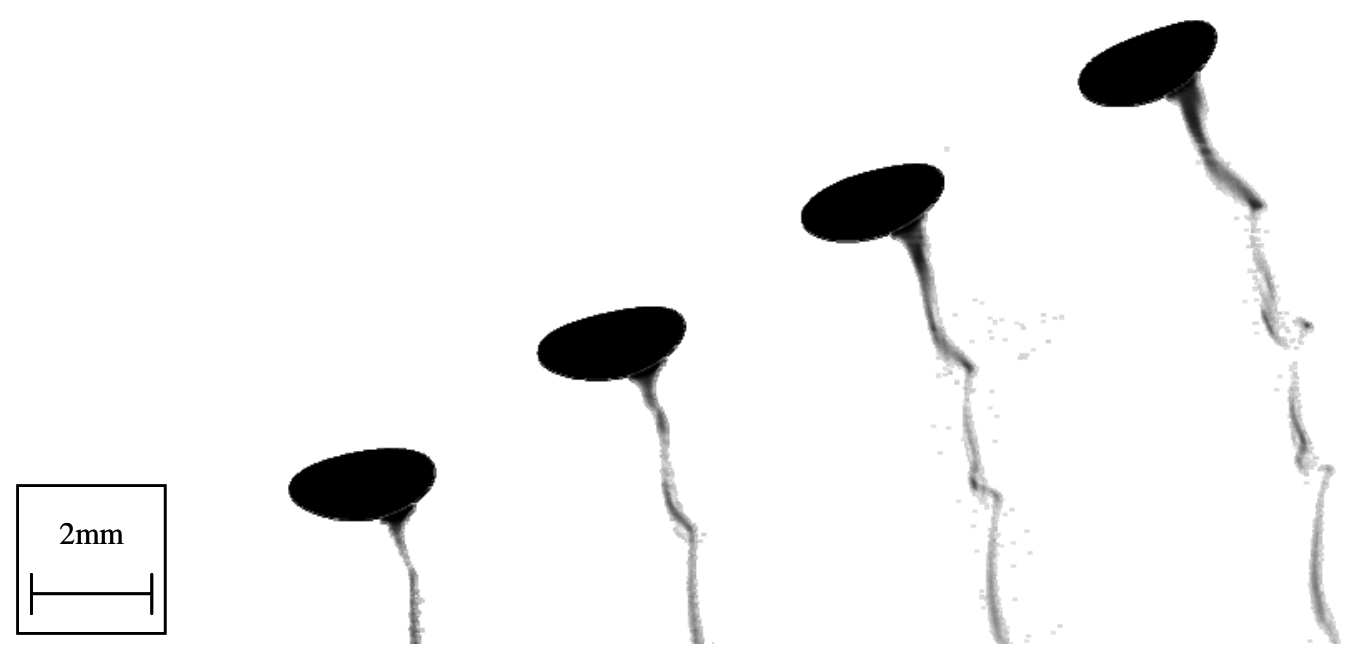
(e) $t_{0}+0.05[\mathrm{~s}]$
(f) $t_{0}+0.06[\mathrm{~s}]$
(g) $t_{0}+0.07[\mathrm{~s}]$
(h) $t_{0}+0.08[\mathrm{~s}]$

(C) Wake motion observed near the first inversion point.

Fig. 4 Wake motion observed around the first inversion point. 
ヘアピン渦に酷似した気泡後流が可視化された，一方(b)においては，ヘアピン渦の一部分が可視化された．本実 験では解像度を優先し，低被写界深度で可視化した。

図 4(B)に気泡が注射針から射出された直後における気泡後流の可視化結果を示す（a)においては，真田ら (20) の可視化結果に類似した, 左右対称な気泡後流が気泡底部から発達していることがわかる. しかし, 気泡の上昇 とともに(b)，(c)，(d)においては，気泡の右底部から後流が発達していることがわかる．Khinast ら $^{(21)}$ は，数值計 算により，気泡後流の形態を分類したが，本研究におけるこの遷移は，気泡後流が“closed wake with recirculation” から, “unsteady wake with vortex shedding”へその形態を変化させた過程を捉えたものであると考えられる.この時, 右エッジ部の曲率 : $\kappa_{R}$ の変動の振幅の最大值が 1.4 [1/mm], 左エッジ部の曲率 : $\kappa_{\mathrm{L}}$ の最大值が $1.2[1 / \mathrm{mm}]$ であり

(右エッジ部の最大值が約 16 \%大きい)，右エッジ部の形状変形が相対的に顕著であると言える．図 4(C)の第一 変向点後において, 気泡後流, 気泡界面運動ともに左右非対称であり, ヘアピン渦の足の位置 (PPHVL: Position of the Point of the Hairpin like Vortex Leg) は僅かな摂動を示した ((e) (h)). これらの結果から, 気泡界面運動と気泡 後流との間には深い相互関係があると考えられる．しかし，このような定性的な考察からは，時間的にどちらの 変動が先であるかを結論づけるには不十分である，そこで，我々は気泡底部の気泡後流の足の位置を定量化し， 界面運動と PPHVL の時系列データを基に，両者の関係を考察した．図５にその定義を示す．図に示寸ように， 気泡の重心位置と気泡底部での気泡後流の足の位置とを結ぶ直線と, 気泡短軸がな寸角度を $\theta$ と定義した. PPHVL の変動は曲率の変動と酷似していることから, その支配的な周波数は $70 \mathrm{~Hz}$ 前後と見積もることが出来る.一方, 気泡短軸の傾きの変動に支配的な周波数は，ジグザグ軌道の周波数 $7 \mathrm{~Hz}$ と同程度であることから ${ }^{(7)}$, 基準線を短 軸とすることにより, PPHVL の変動のみを抽出, 評価できる.

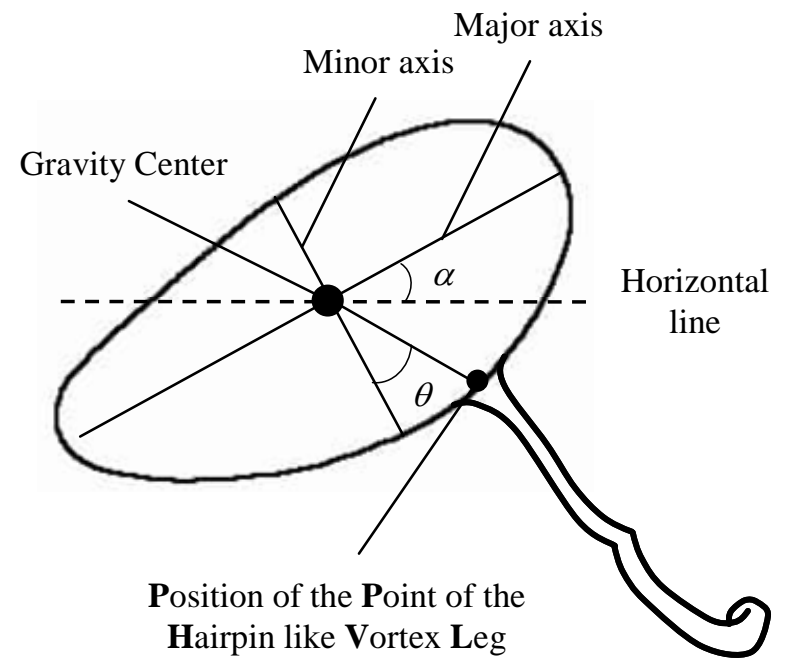

Fig. 5 Definition of PPHVL, $\alpha$ and $\theta$.

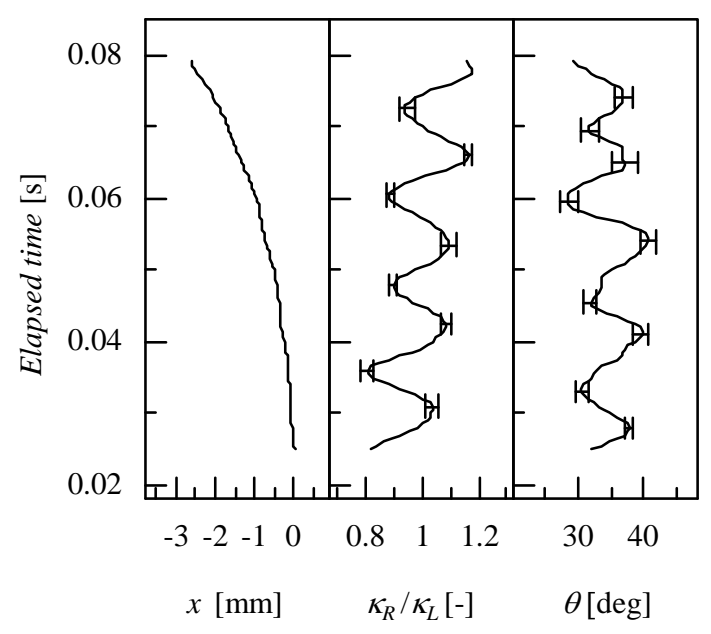

Fig. 6 Relationship between the bubble motion and $\theta$.

図 6 に，気泡重心運動，気泡界面運動， $\theta$ の時系列データ（5回計測した平均值）を示す. 図から明らかなよう に， $\kappa_{R} / \kappa_{L}$ と $\theta$ の波形は酷似している. 変動に支配的な周波数はそれぞれ約 $70 \mathrm{~Hz}$ である. 図において, $t=0.03[\mathrm{~s}]$ では，両変動間に位相差はない.しかしながら，時間の経過とともに， $\theta$ の変動における頂点が， $\kappa_{R} / \kappa_{L}$ のそれよ りも徐々に早くなることがわかる. $t=0.07$ [s]以降においては，両変動間に半周期程度の位相差が生じていること がわかる．ここで相互相関関数を用いて両波形間の位相差を算出したそその結果，本計測範囲においては， $\theta$ の 変動に対し $\kappa_{R} / \kappa_{L}$ が $\pi / 2[\mathrm{rad}]$ 遅れていることがわかった. すなわち気泡後流の挙動が気泡の变形に深い影響を及ぼ していると言える，次節では気泡に働く揚力との関係も含め，後流の運動とジグザグ運動との相互関係を考察す る. 


\section{$3 \cdot 3$ 気泡後流の挙動が気泡重心位置に及ぼす影響, 界面変形との相互関係}

Mougin $ら^{(10)}$, De Vries $ら^{(22)}$, Zenit $ら^{(23)}$ は DNS 及び実験により得られた結果を基に, 単一気泡の直線運動とジ グザグ運動との違いはその後流の挙動にあると報告した，すなわち，気泡後流が不安定化することにより，気泡 後流が気泡に働く揚力を誘起する. 本研究では, 気泡の重心位置の変位から間接的に気泡に働く揚力を見積もる. 式（8）にその定義を示す.

$$
F_{X}=\rho V d^{2} x / d t^{2}
$$

ここで, $\rho\left[\mathrm{kg} / \mathrm{m}^{3}\right]$ は二酸化炭素気泡の密度, $V\left[\mathrm{~m}^{3}\right]$ は二酸化炭素気泡の体積, $x[\mathrm{~m}]$ は水平方向の気泡重心座標, $t$ [s]は時間（画像間隔）である. 図 7 にこの式を用いて算出した揚力変動の時系列データを示す. 揚力変動に支 配的な周波数は約 $70 \mathrm{~Hz}$ であり，気泡界面運動・気泡後流に支配的な周波数と良く一致している.

気泡後流・気泡重心運動・気泡界面運動の相互関係を定量的に考察するために，相互相関関数を用いて各变動 間の位相差を算出した．表 1 に結果を示す．表 1 において，(a)は $F_{x}$ に対する $\theta$ の位相のズレ，(b)は $\kappa_{R} / \kappa_{L}$ に対す る $\theta$ の位相のズレ，(c)は $F_{x}$ に対する $\kappa_{R} / \kappa_{L}$ の位相のズレを示す. C C C は相関係数・ $T_{l}$ は位相差を示す．これらの結 果より, 時間的に一番早い現象が $\theta$, 次に $F_{x}$, 最後に $\kappa_{R} / \kappa_{L}$ であることがわかる. すなわち, それぞれの変動の位 相差の結果から，気泡が直線運動からジグザグ運動に遷移するメカニズムを考察すると，まず，気泡後流が不安 定になり (本研究では, PPHVL の変動), その後, 気泡に働く揚力が誘起されると言える. また，気泡が水平方 向に移動することにより，気液間での相互作用がより非対称性を増し，結果として左右非対称な形状変形をする と考えられる. 気泡の形状変形のメカニズムは，今後さらに詳細に検討していきたい.

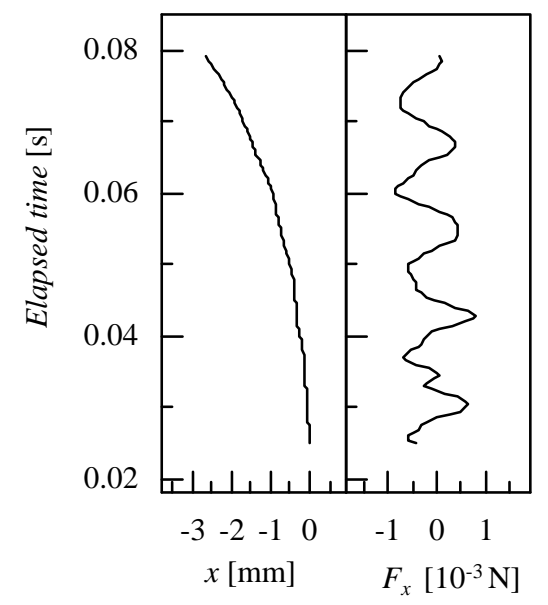

Fig. 7 Lift force acting on the bubble.

Table 1 Time lags between $\theta, F_{X}$ and $\kappa_{R} / \kappa_{\mathrm{L}}$.

\begin{tabular}{|c|c|c|c|}
\hline & (a) $\theta$ to $F_{x}$ & (b) $\theta$ to $\kappa_{R} / \kappa_{L}$ & (c) $F_{x}$ to $\kappa_{R} / \kappa_{L}$ \\
\hline$C c c[-]$ & 0.75 & 0.79 & 0.91 \\
\hline$T_{l}[\mathrm{rad}]$ & $-\pi / 2$ & $-\pi / 2$ & $-\pi / 4$ \\
\hline
\end{tabular}

\section{$3 \cdot 4$ 射出直後の界面変形}

Tomiyama ら ${ }^{(24)}$ が報告しているように, 射出直後の気泡の初期変形はその後の気泡運動を特徵づける. 本研究 では，形状が左右非対称な注射針を用いることで，気泡のドリフト方向を制御している．また，高い再現性の条 件下で実験を行っているため, 射出直後の形状変形が同一であり, その後の気泡の軌跡も常に同一となる. 図 8 に, 気泡射出直後の界面変形の可視化結果を示寸. なお, バックライトとしてハロゲンランプを用い, 撮影時間 : $5000 \mathrm{fps}$, 露光時間 : $20 \mu \mathrm{s}$ で撮影を行った. $t=0.0$ [ms]において気泡が射出されて間もなく左エッジ部において, 
図に灰色の破線で示寸ような曲率の大きい ripple が形成され，それが気泡界面を時計回りに伝播していく様子が 確認できる. 一方で, 右エッジ部においては顕著な界面振動は観察されない. このような左右非対称性により， 前方よどみ点・後方よどみ点共に直線運動のそれとは異なると考えられ，気泡のエッジ部にて生成される渦の量 は均等ではなくなると考えられる. 事実, 図 4(B)において気泡が注射針から射出されてまもなく気泡後流の足の 位置は右へとその位置を遷移させている. 3.3 節で議論したように, 気泡後流は気泡に働く揚力を誘起する. 気泡 後流が不安定になるトリガーは, 気泡射出直後の気泡界面変形により誘起された周囲液相運動の非対称性である と考えられる.

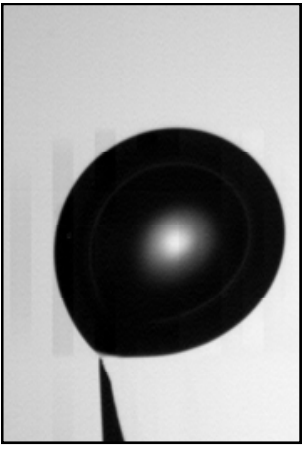

$t=0.0[\mathrm{~ms}]$

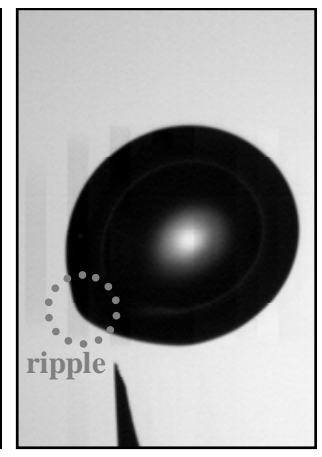

$t=1.0[\mathrm{~ms}]$

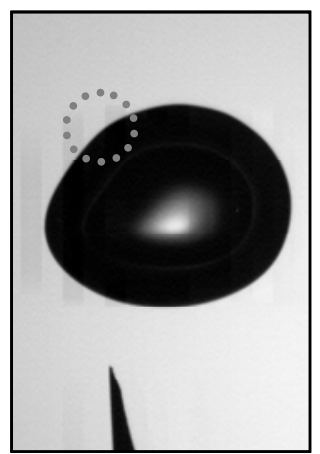

$t=3.0[\mathrm{~ms}]$

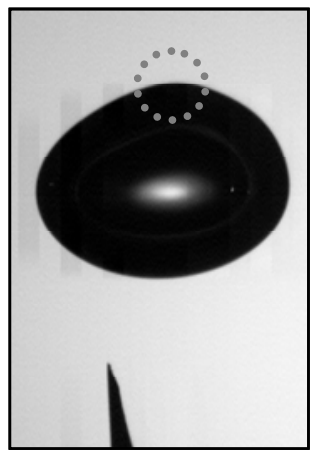

$t=5.0[\mathrm{~ms}]$

Fig. 8 Bubble surface motion observed just after bubble launch.

\section{4. 結言}

本研究では, 気泡運動と気泡後流を同時に可視化することにより, 気泡形状変形・気泡後流の足の位置の変動・ 気泡に働く揚力の相互関係を論じた。気泡の運動を制御し, 高い再現性の条件下で実験を行うことにより, 定量 的かつ統計的な議論を行った．結果として，気泡後流の気泡底部での変動が気泡に働く揚力を誘起することを明 らかにした，気泡の左右非対称性は，気泡が水平方向に移動することによる周囲液相との相互作用により生じる と結論付けた. さらに気泡後流が最初に変動する（不安定になる）原因として, 気泡射出直後の形状変形に着目 した．気泡形状の左右非対称性が気泡の周囲液相運動に非対称性を誘起し，その結果，気泡後流の運動も不安定 に変動すると結論付けた．これらの結果から，気泡が直線運動からジグザグ運動に遷移する際に，気泡後流の変 動が支配的であることを明らかにした．今後の展望として，ジグザグ軌道を呈しかつ異なる径を有する気泡を対 象とし, 本研究と同じ実験・解析を行うことにより, 本研究で提案したメカニズムの有效性をより確かなものに していくことを目標とする.

\section{謝辞}

本研究は, 日本学術振興会科学研究費補助金[基盤研究 A, 課題番号 20246037]の助成を受けて行われた. ここに 記して謝意を表す.

\section{文献}

(1) Saito, T., Kosugi, S., Kajishima, T., Tsuchiya, K., “Characteristics and Performance of a Deep-Ocean Disposal System for Low-Purity $\mathrm{CO}_{2}$ Gas via Gas Lift Effect”, Energy \& Fuels, Vol. 15, (2001), pp. 285-292.

(2) Mudde, R.F., “Gravity-Driven Bubbly Flows”, Annual Review of Fluid Mechanics 2005, (2005), pp. 393-423.

(3) Clift, R., Grace, J.R., Weber, M.E., “Bubbles, Drops, and Particles”, Academic Press, N.Y., (1978).

(4) Lunde, K., Perkins, R.J., "Observations on wakes behind spheroidal bubbles and particles”, ASME Fluids Engineering Division Summer Meeting, (1997), paper 3530. 
(5) Motarjemi, M., Jameson, G.J., "Mass transfer from very small bubble -The optimum bubble size for aeration-”, Chemical Engineering Science, Vol. 33, (1978), pp. 1415-1423.

(6) Brücker, C., "Structure and dynamics of the wake of bubbles and its relevance for bubble interaction”, Physics of Fluids, Vol. 11, No. 7 (1999), pp. 1781-1796.

(7) 宮本悠樹・齋藤隆之, “単一上昇気泡の界面運動とジグザグ上昇運動の相互関係”, 日本機械学会論文集 B 編, Vol. 71, No. 705 (2005), pp. 1307-1313.

(8) Yamamoto, M., Yamada, M., Morikawa, M., Saito, T., “Coupling mechanism between liquid phase motion and mass transfer around single rising bubbles by using PIV/LIF”, Proceedings of 14th International Symposium on Applications of Laser Techniques to Fluid Mechanics, Lisbon, Portugal, (2008).

(9) Magnaudet, J., Mougin, G., “Wake instability of a fixed spheroidal bubble”, Journal of Fluid Mechanics, Vol. 572, (2007), pp. 311-337.

(10) Mougin, G., Magnaudet, J., “Wake-induced forces and torques on a zigzagging/spiraling bubble”, Journal of Fluid Mechanics, Vol. 567, (2006), pp. 185-194.

(11) Shirota, M., Sanada, T., Sato, A., M. Watanabe, "Formation of submillimeter bubble from an orifice using pulsed acoustic pressure waves in gas phase”, Physics of Fluids, Vol. 20, (2008), pp. 043301 1-11.

(12) Saito, T., Sakakibara, K., Miyamoto, Y., Yamada, M., “A study of surfactant effects on the liquid-phase motion around a zigzagging-ascent bubble using a recursive cross-correlation PIV”, Chemical Engineering Journal, Vol. 158, (2010), pp. 39-50.

(13) Tokuhiro, A., Maekawa, M., Iizuka, K., Hishida, K., Maeda, M., “Turbulent flow past a bubble and an ellipsoid using shadow-image and PIV techniques”, International Journal of Multiphase Flow, Vol. 24, (1998), pp. 1383-1406.

(14) Coppeta, J., Rogers, C., "Dual emission laser induced fluorescence for direct planar scalar behavior measurements", Experiments in Fluids, Vol. 25, (1998), pp. 1-15.

(15) Tsuchiya, K., Saito, T., Kajishima, T., Kosugi, S., “Coupling between mass transfer from dissolving bubbles and formation of bubble-surface wave”, Chemical Engineering Science, Vol. 56, (2001), pp. 6411-6417.

(16) Hanyu, K., Saito, T., "Dynamical mass-transfer process of a $\mathrm{CO}_{2}$ bubble measured by using LIF/HPTS visualization and photoelectric probing”, The Canadian Journal of Chemical Engineering, Vol. 88, (2010), pp. 551-560

(17) Lunde, K., Perkins, R.J., “Shape Oscillation of Rising Bubbles”, Applied Scientific Research, Vol. 58, (1998), pp. $387-408$.

(18) Duineveld, P. C., “The rise velocity and shape of bubbles in pure water at high Reynolds number”, Journal of Fluid Mechanics, Vol. 292, (1995), pp. 325-332.

(19) Gaudlitz, D., Adams, Nikolaus A., "Numerical investigation of rising bubble wake and shape variations”, Physics of Fluids, Vol. 21, (2009), pp. 122102 1-9.

(20) Sanada, T., Shirota, M., Watanabe, M., “Bubble wake visualization by using photochromic dye”, Chemical Engineering Science, Vol. 62, (2007), pp. 7264-7273.

(21) Khinast, J., “Impact of 2-D Bubble Dynamics on the Selectivity of Fast Gas-Liquid Reactions”, AIChE Journal, Vol. 47, No. 10 (2001), pp. 2304-2319.

(22) De Vries, A.W.G., Biesheuvel, A., Van Wijngaarden, L., "Notes on the path and wake of a gas bubble rising in pure water", International Journal of Multiphase Flow, Vol. 28, (2002), pp. 1823-1835.

(23) Zenit, R., Magnaudet, J., "Measurement of the streamwise vorticity in the wake of an oscillating bubble", International Journal of Multiphase Flow, Vol. 35, (2009), pp. 195-203.

(24) Tomiyama, A., Celata, G. P., Hosokawa, S., Yoshida, S., "Terminal velocity of single bubbles in surface tension force dominant regime”, International Journal of Multiphase Flow, Vol. 28, (2002), pp. 1497-1519. 